\title{
An exploration of parenting stress in Taiwanese and immigrant mothers
}

\begin{abstract}
A comparative descriptive, cohort study was conducted to assess parenting stress and major difficulties experienced in early motherhood among Taiwanese and immigrant women in Pingtung, southern Taiwan. One hundred and sixty-two Taiwanese and 26 foreign-born Vietnamese mothers were surveyed at 6 weeks postpartum. Both groups of mothers experienced similar parenting difficulties including the establishment of a regular sleeping schedule for the infant, consoling a crying infant, awareness of infant's needs, conflict with family members, and difficulties managing household chores. Curtailment of social activities was reported more often by Taiwanese mothers, while inaccessibility to other experienced mothers and poor maternal-infant bonding were experienced more by immigrant mothers. There were significant differences between groups with high levels of childcare stress and postnatal depressive symptoms reported more often by immigrant mothers. Nurses-midwives and community child health nurses need to be sensitive to the particular difficulties and stresses of parenting in mothers from different backgrounds, and provide effective interventions and support activities for new mothers and their infants.
\end{abstract}

Keywords: child care stress, immigrant women, mothers, parenting stress, postnatal depression. 


\section{Acknowledgement}

The authors deeply appreciate the mothers who gave freely of their time to participate in this study. The authors also profoundly thank Professor Cindy-Lee Dennis for approving the use and translation of the Child Care Stress Checklist. 


\section{Introduction}

Many Asian women of reproductive age migrate in the hope for a better life. ${ }^{1}$ The number of women immigrating to Taiwan for the purposes of marriage exceeded 440,000 in $2011^{2}$ Referred to as foreign brides, women from Vietnam formed the largest group totalling 84315 (accounting for 57.2\% of foreign brides), followed by Indonesia at 27036 (18.3\%), and 8126 Thailand (5.5\%). ${ }^{3}$ Around 1 in 5 marriages in Taiwan are between a Taiwanese national and a foreign bride. ${ }^{3}$

For many women, the experience of pregnancy, giving birth and becoming a mother is an important transition that can be challenging and often affected by life circumstances. Experiences in the postpartum may differ amongst immigrant women, and in comparison with native-born Taiwanese women. Although there is evidence of an adverse relationship between parenting stress and maternal symptoms of depression, there is relatively little research about parenting stress of mothers in Taiwan. Furthermore, women residing in Taiwan's rural areas may be further disadvantaged. The primary aim of this study is to assess parenting stress among Taiwanese mothers and immigrant Vietnamese mothers living in Pingtung County (situated in the southernmost part of Taiwan) and the impact of parenting stress on postpartum depression (PPD) symptoms in these women.

\section{Literature review}

The birth of an infant brings new and challenging demands for parents. Women may be especially affected as they are traditionally expected to take primary responsibility for the infant's care. ${ }^{4}$ For many women, having an infant may change their lifestyle considerably, creating stress and contributing to the development of mental health problems. ${ }^{5}$ High levels of intrapersonal and situational stress may result from women's expectations and their subsequent experience of motherhood. ${ }^{6}$ Moreover inadequate childbirth preparation and 
infant care guidance may be associated with increasing risk of maternal distress and postnatal depression (or PPD). ${ }^{7,8}$

Child care responsibilities in new and changing situations may act cumulatively to diminish maternal well-being and confidence in parenting. Postnatal depression is known to be a common affective disorder in women, with the most recent study indicating a prevalence of about $20 \%$ in Asian countries. ${ }^{9}$ Symptoms of PPD can include despondent mood, feelings of inadequacy as a parent, sleep and appetite disturbances, and impaired concentration. ${ }^{10}$ Women with PPD who go undetected and untreated are at risk for immediate harm and potential lifelong sequelae for themselves and their family. ${ }^{11}$ Although the specific cause of PPD remains unclear, good quality meta-analyses have identified statistically significant associations between PPD and several psychosocial risk factors including poor social support, antenatal depression, life stress, difficulties in the marital relationship, depression history, infant temperament, socioeconomic status, child care stress, low self-esteem, unplanned / unwanted pregnancy, and antenatal anxiety. ${ }^{12,13}$ Moreover, ethnicity, cultural issues and migration have also received some consideration. For example, recently immigrated women in Canada, had a high risk of PPD and difficulties with early mothering. ${ }^{14}$ In addition, Asian immigrants in North America who experienced more negative life events and stress were at greater risk for depression than the US population. ${ }^{15}$ Different cultural norms and parenting practices may also pose problems for immigrant women, placing them at risk for psychological distress and impaired ability to parent effectively. ${ }^{14}$

\section{Methods}

\section{Design}

A comparative, descriptive cohort design was used. A survey was conducted with 2 groups of postpartum mothers, using self-report questionnaires.

\section{Sample}


Women were invited to participate if they were either Taiwanese women or of Vietnamese descent and recently immigrated to Taiwan ( $<3$ years ago), at least 18 years of age, and expected to give birth to a live, singleton infant. Women with a current or past mental health problem or a stillbirth, late neonatal death, or a live birth with a congenital anomaly were excluded from the study.

\section{Measures}

The survey was available in Chinese and Vietnamese translated versions and included demographic questions, the Edinburgh Postnatal Depression Scale (EPDS), and the Child Care Stress Checklist (CCSC). Demographic questions included ethnicity, socio-demographic status (age, education, type of job, marital status, and length of residence in Taiwan), and 4 items assessed parity, mode of birth, gender of infant, and newborn birth weight.

The 10-item EPDS was chosen as a screening instrument for postnatal depression because it has well-documented reliability and validity in multiple languages including Chinese and Vietnamese ${ }^{16-18}$. For each item on the EPDS, respondents rate how they felt in the past week, on a scale of 0 (No, not at all) to 3 (As much as I always have). Scores range from 0 to 30, with higher scores implying greater distress. As recommended by Cox and Holden ${ }^{16}$ and Gibson et al. ${ }^{19}$, a cutoff point of 13 or more was used for the presence of probable postnatal depression. Cronbach $\alpha$ coefficients in the present study were 0.86 (for the Chinese version) and 0.71 (for the Vietnamese version), respectively.

Parenting stress was determined by using the 23-item CCSC. ${ }^{20}$ Mothers assess the occurrence of postnatal events related to child care (e.g., "Difficulty quietening my baby"; "Having trouble establishing regular feeding times") on a yes-no scale to produce a summative score ranging from 0 to 23, with higher scores indicating higher levels of child care stress. The CCSC was tested with 501 mothers at 4 and 8 weeks postpartum and demonstrated good reliability (Cronbach $\alpha=0.81$ ). ${ }^{20}$ In the current study, the CCSC was translated and culturally adapted to the Chinese and Vietnamese versions with the author's ${ }^{20}$ permission. The translation 
process followed the principles outlined by Haddad et al. ${ }^{21}$ regarding cross-cultural research methods. The process was as follows:

1. The researcher (Ying) approached 3 Vietnamese postgraduate students who had studied in an English-speaking country for more than 1 year. They completed the initial translation separately and then discussed each item with each other. After discussion, there was a single, reconciled Vietnamese version that was deemed to be conceptually equivalent to the English version.

2. Back-translation was performed by a lay bilingual Vietnamese woman with a Bachelors degree and had been married to a Taiwanese man for more than 3 years. The back-translated scale reconciled with the Vietnamese version. There was a key-informant dialogue between the researcher and the back-translator, with the aim of enhancing the cultural relevance of each item.

3. Piloting of the Vietnamese version of the CCSC was conducted with 10 Vietnamese immigrant women. If $20 \%$ or more participants did not understand an item, the question was modified and tested again. No item of the CCSC was noted to be ambiguous or irrelevant to participants.

For the Chinese version of the CCSC, the translation process was similar to that of the Vietnamese version. The Cronbach $\alpha$ coefficient for the CCSC was 0.85 for both Chinese and Vietnamese versions.

\section{Procedure}

The research team consisted of 2 certified nurse-midwives with doctoral degrees, a Taiwanese doctoral student, and 4 Vietnamese interpreters who assisted participants to complete the form as needed. Eligible women, in their last trimester of pregnancy and attending an antenatal appointment were asked by clinic staff if they wished to participate in the study. Women were then approached by the researcher who provided information about the study, obtained informed consent, and asked the women to complete the antenatal 
survey forms. Participants could complete either the Chinese or Vietnamese questionnaire version. At around 6 weeks postpartum, all recruited women were re-contacted in person or by phone to assess levels of child care stress and prevalence of maternal depressive symptoms. There was no remuneration for participation. Data were collected between February and July 2007. The study had approval from the Human Research Ethics Committee of Griffith University, Australia (NRS/36/05/HREC) and the relevant hospital committees in Taiwan (IRB 200601).

\section{Data analyses}

All analyses were conducted with SPSS (Version 12.0). Descriptive statistics, including frequencies and percentages for categorical variables, and means and standard deviations for continuous variables were used to characterize the sample. The estimated sample size was determined by the generally accepted rule of $n=2+8\left(1-r^{2} / r^{2}\right)^{22}$, where $r$ ranges from 0.2 to 0.5, with type I error 0.05 and power $0.8 .^{22}$ An estimated sample ranging from 44 to 194 was required. Pearson correlation coefficients $(r)$ were calculated for the CCSC and EPDS scores. The nonparametric Mann-Whitney $U$ test and the Fisher's exact test were used to determine any differences between groups. Two tailed $p$ values at a 5\% level of significance were used.

\section{Results}

\section{Participant characteristics}

As shown in Table 1, a total of 162 Taiwanese women at six weeks postpartum (mean days after birth $=44.2$, SD $=19.3$ ) completed the surveys and 26 Vietnamese women responded. Among the Taiwanese participants, the age range was between 18 and 39 years, with a mean age of 29.4 years ( $\mathrm{SD}=4.42)$. Most women $(73.8 \%)$ were between 25 and 34 years of age; 13.2\% were younger than 25 years and $13.1 \%$ were 35 years or more. More than a half of participants $(51.6 \%, \mathrm{n}=83)$ possessed a high school diploma and $42.2 \%(\mathrm{n}=68)$ had obtained a college diploma or university degree. More than half (56.2\%) were first-time 
mothers, more than one-third $(36.4 \%)$ had 1 child and 7.4\% $(\mathrm{n}=12)$ had 2 or more children. Sixty percent of women $(n=98)$ had a vaginal birth and $40 \%(n=64)$ had a cesarean section. Of the infants born to Taiwanese women, $56 \%$ were boys, and $44 \%$ were girls. The proportion of infants weighing less than $2500 \mathrm{~g}$, defined as low-birth-weight infants, was approximately $4.3 \%$ of the sample. The majority of infants (70\%) weighed $3000 \mathrm{~g}$ or more.

The mean age of Vietnamese mothers was 24.5 years $(\mathrm{SD}=3.49)$; the mean years of education were $9(\mathrm{SD}=2.36)$ years. Approximately 39.1\% $(\mathrm{n}=9)$ had attended secondary school, 39\% $(n=9)$ had tertiary education, and one-fifth $(21.8 \%, n=5)$ had only primary (elementary) education or less. All of the Vietnamese mothers were married and lived with their Taiwanese husbands or in-laws. The majority of women (80.8\%) were not employed outside the home (either full-time or part-time). For $60.9 \%$ of Vietnamese mothers $(n=14)$, it was their first child. The remaining participants $(39.1 \%$; $n=9)$ were multiparous. Nearly $16 \%$ of Vietnamese mothers reported a cesarean birth. Fifty percent of Vietnamese mothers $(n=13)$ gave birth to a male infant, and mean birth weight of 26 infants was $3071.5 \mathrm{~g}$ (range $=2200 \sim 3640 \mathrm{~g})$.

Insert Table 1 about here

\section{Analysis of standardized measures}

As shown in Table 2, nearly 26\% of Vietnamese mothers (6/26), compared with $24 \%$ of Taiwanese mothers (39/162), had probable postnatal depression. The EPDS mean score was $9.09(\mathrm{SD}=5.60)$ for Taiwanese mothers and $10.35(\mathrm{SD}=4.42)$ for Vietnamese mothers, but this difference was not statistically significant (Mann-Whitney $U$ test, $p>.05$ ).

For Taiwanese women, the mean CCSC score was $5.94(\mathrm{SD}=4.71)$, indicating that approximately 6 child care events were stressful. The Vietnamese mothers reported higher stress $($ mean $=7.15, \mathrm{SD}=4.90)$, and this was statistically significant $(U=945, Z=-4.52, p=$ .001). There was a significant positive correlation between the EPDS and CCSC scores for both groups of women ( $r=0.57$ for Taiwanese, $r=0.61$ for Vietnamese, $p<.01$ ). 


\section{Insert Table 2 about here}

As shown in Table 3, there were some areas of congruence and differences in reported parenting stress by each group. Areas of highest parenting stress were "trouble establishing regular sleep” (corresponding to item 15), “conflict with family” (corresponding to item 1), "upset house more than usual” (corresponding to item 7), “difficulties quietening baby (corresponding to item 9), and "unrecognized baby needs" (corresponding to item 16). However, a group comparison of individual items on the CCSC revealed significant differences in the percentage of mothers scoring items $11,12,13,17,19$, and 20 . Nearly $70 \%$ of Vietnamese mothers were concerned they might "take longer to learn to love baby" (corresponding to item 13), while only 31\% of Taiwanese mothers were concerned with this issue $(p<.01)$. In addition, Vietnamese mothers reported significantly more perceived stress related to "a lack of experienced mothers to consult" (corresponding to item 20) than Taiwanese mothers $(p=.01)$. Compared with Taiwanese mothers, Vietnamese mothers were concerned about "baby health problems" (corresponding to item 11) ( $p=.02)$, "maternal health problems associated with childbirth" (corresponding to item 12) ( $p=.05)$, and "having a discontented baby” (corresponding to item 17) $(p=.05)$. Taiwanese mothers were more likely to experience stress from the "absence of previous social activities" (corresponding to item 19) than foreign-born mothers $(p=.01)$.

Insert Table 3 about here

\section{Discussion}

A consistent association was found between parenting stress and postpartum depressive symptoms in Taiwanese and Vietnamese immigrant women. Depressed mothers were more likely to perceive events associated with domestic chaos and conflict and difficulties settling the infant (items $1,7,9,15,16$ ) as causing them stress. This result is similar to that of Beck ${ }^{23}$, who found that stressful events associated with infant care contributed to postnatal depression 
in North American women. Correspondingly, Dennis and Ross ${ }^{24}$ also found that Canadian mothers with high depression scores were significantly more likely to report that their infants cried often, and they were woken frequently between 10 PM and 6 AM. Consequently, mothers often felt fatigued. Similar to the finding of the current study, key elements of child care stress have been reported to include difficulties in consoling the infant when crying, difficulties around feeding, and infant health problems ${ }^{24,25}$.

Among both groups of participating mothers, they often experienced conflict stemming from child care and general household duties (i.e., item 1). According to a recent national government survey ${ }^{26}$, over a third of Taiwanese adults aged between 20 and 49 years live with their parents. In addition, more than half of foreign-born Vietnamese women married to Taiwanese men coresided with their parents-in-law. ${ }^{26}$ It is reasonable to assume that there are both benefits and hazards of intergenerational coresidence that may influence maternal well-being. A potential area of difficulty may be related to adherence to traditional practices around infant care, which may contribute to marital disharmony and conflict. ${ }^{27,28}$

The nature of parenting stress also differed among these 2 groups of women. More Taiwanese mothers after birth were relatively uninvolved in formerly leisure or social activities than Vietnamese immigrant mothers. (i.e., item 19). Perhaps, the most obvious explanation for this discrepancy is that Vietnamese mothers had limited social contacts and lacked social connection before and during pregnancy. There may have been no significant change in the nature and extent of their social contacts during the postpartum period.

For Taiwanese mothers, social activities might be an important source of pleasure, and a decline in social activities may have adversely affected their health and well-being. Curtailment of social contact has been associated with an increased risk of postnatal depression. ${ }^{28}$ More specifically, the transition from being a childless woman to becoming a mother can create a significant shift in lifestyle and role expectations for Asian women. The majority of married women are traditionally expected to undertake most of the household 
work, provide care to family members, and look after small children. Motherhood restricts women's activities outside the home. Time constraints arising from more essential activities (such as child care tasks) can sometimes create difficulties, especially for mothers who have experienced a substantial shift in their career. ${ }^{29}$ Several scholars have noted that even if the employed mother returned to work following childbirth, some felt alienated from their workmates and supervisors who may not relate to their new motherhood status. ${ }^{29,30}$ Furthermore, working mothers may feel isolated from local networks of other mothers because of lack of time or inconvenience in accessing existing services ${ }^{29,31}$. Therefore, diminished opportunity for social interaction, time constraints of childcare, and/or lack of disposal income could predispose mothers to depression.

Differences were also noted in regards to parenting advice and support. Nearly $40 \%$ of Vietnamese mothers compared to $15 \%$ of Taiwanese mothers reported that the connection with other experienced mothers was unavailable or absent. It seems likely that the Vietnamese mothers could not access experienced mothers to share child-rearing issues, discuss their concerns, or receive advice on matters related to mothering due to their restricted social network. The lack of parenting support faced by Vietnamese mothers might also stem from language obstacles and other barriers (eg, poor literacy, lack of disposable income, and transport) to accessing other mothers, professionals or lay persons. These factors may contribute to parenting stress and development of depressive symptoms. The results of the present study were consistent with the prior studies that found immigrant women with limited official language proficiency (such as Mandarin, English) were unable to communicate easily and effectively with people in the host country and had poorer levels of social support. ${ }^{31,32}$

Another area of concern related to construct a loving relationship and the intimacy of newborn baby. Nearly twice as many Vietnamese mothers responded taking longer time to execute, compared with Taiwanese mothers (i.e., item 13). A previous study demonstrated 
that a loving relationship between mothers and their infants (maternal-infant bonding) is beneficial to the emotional well-being of both. ${ }^{33}$ In contrast, deficits in maternal behaviours or negative attitudes can often profoundly influence infants in areas such as cognition, language, and general health. ${ }^{34}$ As Rubin ${ }^{35}$ noted, "binding-in" to the infant is one of the tasks in maternal role attainment that begins during pregnancy and extends through the 6 months following birth. According to Mercer, ${ }^{36}$ maternal role attainment is an interactional and dynamic process whereby a woman learns mothering behaviours and becomes comfortable with capability to care for the infant. From this point of view, when a mother becomes attached to her infant, she becomes involved in the role, and expresses pleasure and gratification in the role. However, emotional separation has significant impact on bonding development, which can be detrimental when the mother is experiencing some trauma that distracts from the child. ${ }^{34,37}$

Overall, there were significant differences among postpartum Vietnamese and Taiwanese mothers in terms of levels and sources of child care stress. These findings complement evidence from the study with multiethnic samples in North America ${ }^{38}$, which suggests that maternal child care stress is associated with an increased risk of PPD. Furthermore, emotional distress can interfere with mother-infant bonding and create difficulties in day-to-day infant care ${ }^{35}$.

\section{Limitations}

This study was limited by low response rates among immigrant women and sample attrition. Although it was able to successfully recruit Vietnamese foreign brides through antenatal clinics in Taiwan, it was difficult to provide follow-up in their community. Predominantly, immigrant participants lived in scattered rural settlements near the rocky southern coast of Taiwan. Their geographic isolation contributed to their nonattendance at hospital clinics and difficulties with follow-up contact. ${ }^{31}$ It could be that nonresponders in both groups had different experiences to those who completed the postpartum surveys. It may also be 
culturally challenging for women of Chinese decent to openly express their emotional distress and difficulties with parenting. ${ }^{30,39}$ As such, the results may be an under-estimation of the true distress and difficulties being experienced. There was a delay in publishing the results of this study due to significant life changes experienced by members of the research team, however, the review of the literature and current clinical experience confirms a continuing lack of research with these groups of women and that their difficulties are not being addressed by health services.

\section{Conclusions and Implications}

This study found that immigrant childbearing women in a new country were at increased risk of poor emotional health and parenting stress. The experience of immigrant Vietnamese mothers related to their limited personal and social resources (knowledge, skills, or networks) which diminished their ability to cope with motherhood. Conversely, Taiwanese mothers felt socially isolated and constrained by traditional child care practices. Health professionals need to be aware of different sources of child care stress and offer new mothers a range of educational and support options such as professionally led support groups, peer support, and lay home visiting. Providing referral information and links to other experienced mothers in the same region may also benefit postnatal mothers. 


\section{References}

1. The United Nations Population Fund (UNFPA). Migration: A World on the Move. http://www.unfpa.org/pds/migration.html Accessed March 12, 2014.

2. Ministry of the Interior (shortened to MOI). Taiwan. (2011). Statistical yearbook of the immigration (in Chinese). http://www.immigration.gov.tw/mp.asp?mp=1. Accessed May 25, 2013.

3. National immigration agency (shorten as NIA). Taiwan. (2011). Educational profile of 6-to15-year-old children of immigrants (in Chinese). https://stats.moe.gov.tw/files/analysis/son_of_foreign_100.pdf. Accessed May 25, 2013.

4. Deave T, Johnson D, Ingram J. Transition to parenthood: The needs of parents in pregnancy and early parenthood. BMC Pregnancy Childbirth. 2008; 8(30): 1-11.

5. Katz-Wise SL, Priess HA, Hyde JS. Gender-role attitudes and behavior across the transition to parenthood. Dev Psycho. 2010; 46(1): 18-28.

6. Biehle SN, Mickelson KD. First-time parents' expectations about the division of childcare and play. J Fam Psychol. 2012; 26(1): 36-45.

7. Alderdice F, McNeill J, Lynn F. A systematic review of systematic reviews of interventions to improve maternal mental health and well-being. Midwifery. 2013; 29(4): 389-399.

8. Dennis CL, Creedy D. Psychosocial and psychological interventions for preventing postpartum depression. Cochrane Database Syst Rev. 2004; (4): CD001134.

9. Roomruangwong C, Epperson CN. Perinatal depression in Asian women: Prevalence, associated factors, and cultural aspects. Asian Biomed. 2011; 5(2): 179-193.

10. American Psychiatric Association. Diagnostic and Statistical Manual of Mental Disorders DSM-5 5th ed. Washington, DC: American Psychiatric Association; 2013.

11. Goodman SH, Rouse MH, Connell AM, Broth MR, Hall CM, Heyward D. Maternal depression and child psychopathology: A meta-analytic review. Clin Child Fam Psych. 2011; 14(1): 1-27.

12. Leigh B, Milgrom J. Risk factors for antenatal depression, postnatal depression and parenting stress. BMC Psychiatry. 2008; 8(24): 1-11.

13. Leung BM, Kaplan BJ. Perinatal depression: Prevalence, risks, and the nutrition link--a 
review of the literature. J Am Diet Assoc. 2009; 109(9): 1566-1575.

14. Ross LE, Campbell VLS, Dennis CL, Blackmore E R. Demographic characteristics of participants in studies of risk factors, prevention, and treatment of postpartum depression. Can J Psychiat. 2006; 51(11): 704-710.

15. Bernstein KS, Park SY, Shin J, Cho S, Park Y. Acculturation, discrimination and depressive symptoms among Korean immigrants in New York city. Community Ment Health. 2011; 47(1): 24-34.

16. Cox J, Holden J. Perinatal mental health - A guide to the Edinburgh Postnatal Depression Scale. London: Gaskell; 2003.

17. Fisher JR, Morrow MM, Ngoc NT, Anh LT. Prevalence, nature, severity and correlates of postpartum depressive symptoms in Vietnam. BJOG. 2004; 111(12): 1353-1360.

18. Teng HW, Hsu CS, Shih SM, Lu ML, Pan JJ, Shen WW. Screening postpartum depression with the Taiwanese version of the Edinburgh Postnatal Depression Scale. Compr Psychiatry. 2005; 46(4): 261-265.

19. Gibson J, McKenzie-McHarg K, Shakespeare J, Price J, Gray R. A systematic review of studies validating the Edinburgh Postnatal Depression Scale in antepartum and postpartum women. Acta Psychiat Scand. 2009; 119(5): 350-364.

20. Dennis CL. The effect of peer support on postpartum depression: A pilot randomized controlled trial. Can J Psychiat. 2003; 48(2): 115-124.

21. Haddad LG, Shotar A, Younger JB, Alzyoud S, Bouhaidar CM. Screening for domestic violence in Jordan: Validation of an Arabic version of a domestic violence against women questionnaire. Int J Womens Health. 2011; 3: 79-86.

22. Norman G, Monteiro S, Salama S. Sample size calculations: Should the emperor's clothes be off the peg or made to measure? BMJ. 2012; 345(e5278): 1-4.

23. Beck CT. Predictors of postpartum depression: An update. Nurs Res. 2001; 50(5): 275-285.

24. Dennis CL, Ross L. Relationships among infant sleep patterns, maternal fatigue, and development of depressive symptomatology. Birth. 2005; 32(3): 187-193.

25. Bayer JK, Hiscock H, Hampton A, Wake M. Sleep problems in young infants and maternal mental and physical health. J Paediat Child Health. 2007; 43(1-2): 66-73.

26. Directorate General of Budget, Accounting and Statistics Executive Yuan, Taiwan. 
http://eng.dgbas.gov.tw/mp.asp?mp=2 Accessed May 25, 2013.

27. Leung SSK, Lam TH. Group antenatal intervention to reduce perinatal stress and depressive symptoms related to intergenerational conflicts: A randomized controlled trial. Int J Nurs Stud. 2012; 49(11): 1391-1402.

28. Wong J, Fisher J. The role of traditional confinement practices in determining postpartum depression in women in Chinese cultures: A systematic review of the English language evidence. J Affect Disord. 2009; 116(3): 161-169.

29. Seto M, Morimoto K, Maruyama S. Work and family life of childrearing women workers in Japan: Comparison of non-regular employees with short working hours, non-regular employees with long working hours, and regular employees. J Occup Health. 2006; 48(3): 183-191.

30. Edhborg M, Friberg M, Lundh W, Widstrom AM. "Struggling with life": Narratives from women with signs of postpartum depression. Scan J Public Health. 2005; 33(4): 261-267.

31. Chen W, Shiao WB, Lin BYJ, Lin CC. Rural and urban married Asian immigrants in Taiwan: Determinants of their physical and mental health. J Immigr Minor Health. 2013; 15(6): 1038-1047.

32. Leu J, Walton E, Takeuchi D. Contextualizing acculturation: Gender, family, and community reception influences on Asian immigrant mental health. Am J Community Psychol. 2011; 48(3-4): 168-180.

33. McMahon CA, Byranne B, Kowalenko NM, Tennant CC. Maternal attachment state of mind moderates the impact of postnatal depression on infant attachment. J Child Psychol Psychiatry. 2006; 47(7): 660-669.

34. Zauderer CR. A case study of postpartum depression and altered maternal-newborn attachment. Am J Matern Child Nurs. 2008; 3(3): 173-178.

35. Rubin R. Maternal identity and the maternal experience. New York: Springer; 1984.

36. Mercer RT. Becoming a mother: Research on maternal identity from Rubin to the present. New York: Springer; 1995.

37. Moehler E, Brunner R, Wiebel A, Reck C, Resch F. Maternal depressive symptoms in the postnatal period are associated with long-term impairment of mother-child bonding. Arch Womens Ment Health. 2006; 9(5): 273-278. 
38. Kinsey CB, Roberts KB, Zhu J, Kjerulff KH. Birth-related, psychosocial, and emotional correlates of positive maternal-infant bonding in a cohort of first-time mothers. Midwifery. 2014; (in Press): 1-7.

39. Kalibatseva Z, Leong FTL. Depression among Asian Americans: Review and recommendations. Depress Res Treat. 2011; 2011:1- 9. 
Table 1: Demographic and obstetric characteristics of participants

Variables

Maternal age, $Y$

Taiwanese women

$$
\left(n_{1}=162\right)
$$

160

26

$\operatorname{Mean}_{1}=29.4$

Mean $_{2}=24.5$

$<20$

$20 \sim 24$

$25 \sim 29$

$30 \sim 34$

35 39

Missing data

Marital status

Married

Unmarried

(single, divorce, separate)

Duration of married life, mo

$\operatorname{Mean}_{2}=19.0$

Valid number

Missing data

17

Education level

9-y schooling

( $\mathrm{n}=5$ : Elementary)

$$
\begin{aligned}
& \text { 12-y school } \\
& >12-y \text { schooling }
\end{aligned}
$$

Missing data

\section{Health insurance}

\section{coverage}

$$
\begin{aligned}
& 1 \text { (NHI) } \\
& >1
\end{aligned}
$$

Occupation

68

1

Home-based

$$
\begin{aligned}
& \text { Housewife(none) } \\
& \text { Domestic Sidelines }
\end{aligned}
$$

3.8

53.8

30.8

11.5

Mean 
Outside

Part-time jib
Full-time job
Boss
Missing data

$5 \quad 3.1 \quad 0$

$\begin{array}{lll}71 & 44.1 & 2\end{array}$

7.7

$\begin{array}{lll}6 & 3.7 & 0\end{array}$

Missing data

Gross Family Income 153

26

$<30,000$

23

15.0

43.5

$30,000 \sim 50,000$

41.8

47.8

$>50,000$

43.2

8.7

Missing data

$(6$

9

3

Obstetric variables

Parity

Nulliparous

91

56.2

60.9

Multiparous

71

43.8

39.1

Missing data

162

9

3

No. of children

26

None

91

56.2

60.9

1

59

36.4

30.4

$>1$

12

7.4

8.7

Missing data

1

Feeling toward pregnancy

Negative ( No special, very unhappy, 7

or not very unhappy)

$\begin{array}{ll}\text { Mixed } & 27 \\ \text { Pleased } & 84 \\ \text { Overjoyed } & 44\end{array}$

Missing data

27.2

\section{Mode of birth}

Normal Spontaneous Delivery 
Neonatal weight, $g$

$\operatorname{Mean}_{2}=3071.5$

$<2500 \mathrm{~g}$

$2500 \sim 3000 \mathrm{~g}$

$3000 \sim 3500 \mathrm{~g}$

$3500 \sim 4000 \mathrm{~g}$

$\begin{array}{rrrr}7 & 4.3 & 2 & 7.7 \\ 42 & 25.9 & 9 & 34.6 \\ 85 & 52.5 & 12 & 46.2 \\ 28 & 17.3 & 3 & 11.5\end{array}$

Abbreviation: NHI, National Health Insurance in Taiwan 2 
Table 2: Means, standard deviations, and ranges of the EPDS and CCSC scales

\begin{tabular}{llccc}
\hline & Postpartum & Postpartum & \\
& & $\begin{array}{c}\text { Taiwanese mothers } \\
\left(\mathrm{n}_{1}=162\right)\end{array}$ & $\begin{array}{c}\text { Vietnamese mothers } \\
\left(\mathrm{n}_{2}=26\right)\end{array}$ & $p$ (2 tailed) \\
PDS Cutoff $\geq 13$ & mean \pm SD (range) & $9.09 \pm 5.60(0 \sim 24)$ & $10.35 \pm 4.42(3 \sim 23)$ & \\
Below $(0 \sim 12)$ & $n(\%)$ & $123(75.9)$ & $17(73.9)$ & .367( \\
Above $(13 \sim 30)$ & & $39(24.1)$ & $6(26.1)$ & $N S)$ \\
CCSC $^{\mathrm{b}}$ & & & 3 (missing data) & $.000^{\mathrm{b}}$ \\
\hline
\end{tabular}

Abbreviation: CCSC, Child Care Stress Checklist; EPDS, Edinburgh Postnatal Depression Scale; NS, not significant

Statistical significance determined using the Mann-Whitney $U$ Test

в $p \quad<.011$ 


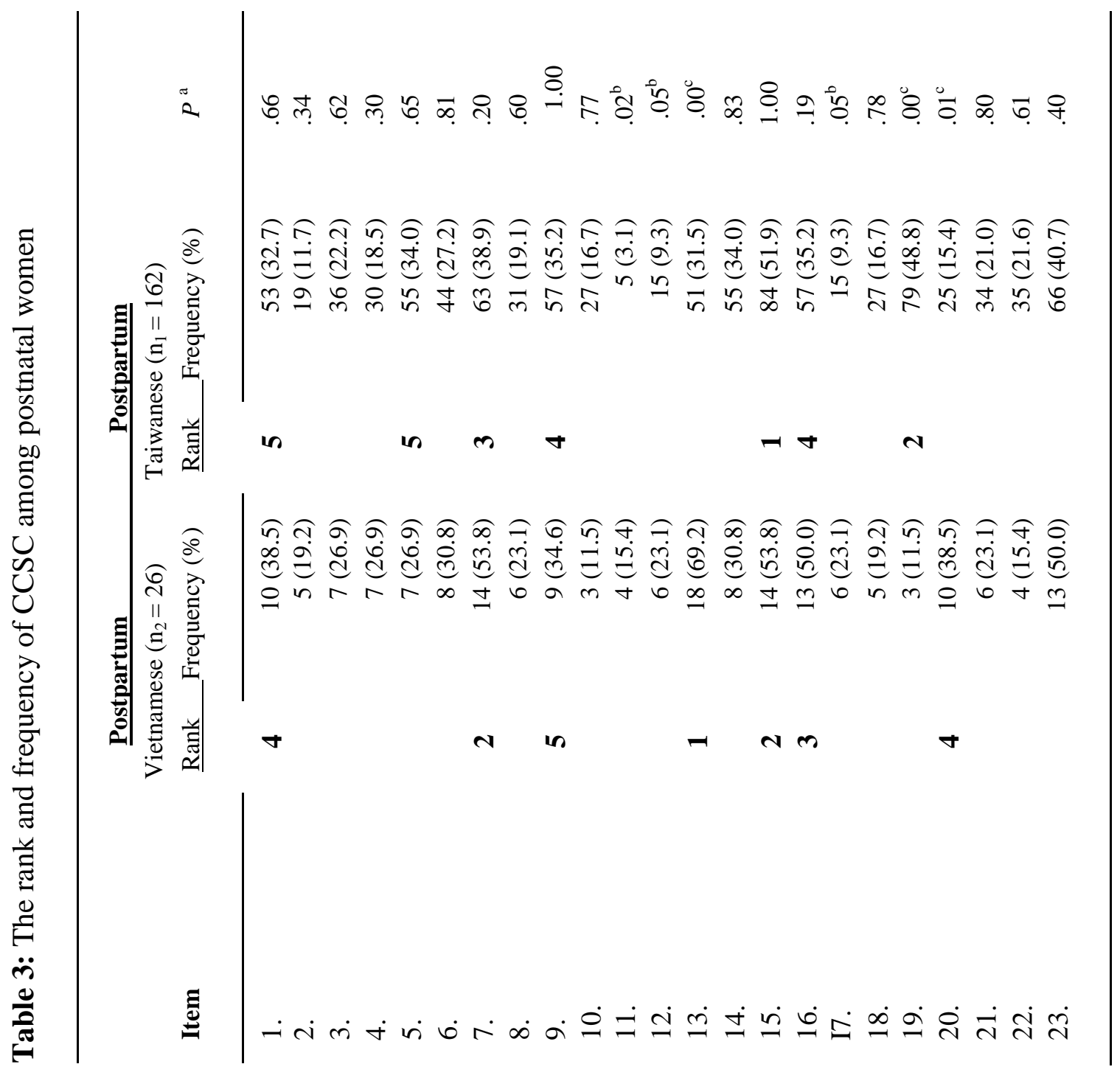




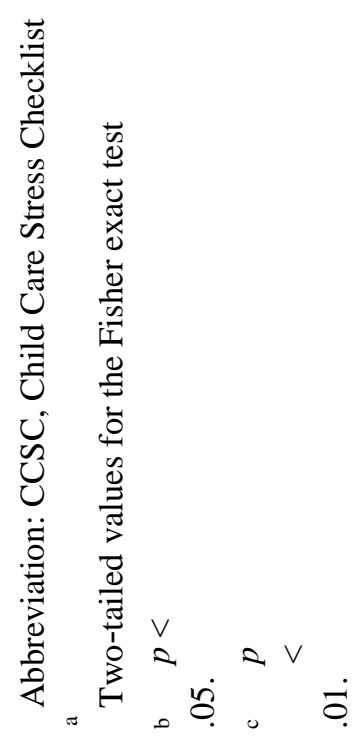

